\title{
Personal protection of long lasting insecticide-treated nets in areas of Anopheles gambiae s.s. resistance to pyrethroids Roch K Dabiré*1,2, Abdoulaye Diabaté ${ }^{1,2}$, Thierry Baldet ${ }^{3}$, Léa Paré-Toé2, Robert T Guiguemdé2, Jean-Bosco Ouédraogo ${ }^{1,2}$ and Ole Skovmand ${ }^{4}$
}

\author{
Address: ${ }^{1}$ IRSS, Direction régionale de Bobo-Dioulasso, BP 545 Bobo-Dioulasso, Burkina Faso, France, ${ }^{2}$ Centre Muraz, BP 390 Bobo-Dioulasso, \\ Burkina Faso, France, ${ }^{3}$ CIRAD-EMVT, Campus International de Baillarguet 34398 Montpellier Cedex 5, France and ${ }^{4}$ Intelligent Insect Control, \\ Montpellier, France \\ Email: Roch K Dabiré* - dabire_roch@hotmail.com; Abdoulaye Diabaté - a_diabate@hotmail.com; Thierry Baldet - thierry.baldet@cirad.fr; \\ Léa Paré-Toé - lea_toe@yahoo.com; Robert T Guiguemdé - rguiguemde@yahoo.fr; Jean-Bosco Ouédraogo - jb_ouedraogo@hotmail.com; \\ Ole Skovmand - ole.skovmand@insectcontrol.net \\ * Corresponding author
}

Published: 10 February 2006

Malaria Journal 2006, 5:12 doi:10.1186/1475-2875-5-12

This article is available from: http://www.malariajournal.com/content/5/I//2

(C) 2006 Dabiré et al; licensee BioMed Central Ltd.

This is an Open Access article distributed under the terms of the Creative Commons Attribution License (http://creativecommons.org/licenses/by/2.0), which permits unrestricted use, distribution, and reproduction in any medium, provided the original work is properly cited.
Received: 28 July 2005

Accepted: 10 February 2006

\begin{abstract}
Background: The development of mosquito nets pre-treated with insecticide, Long Lasting Impregnated Nets (LLINs) that last the life span of the net, is a solution to the difficulty of the reimpregnation of conventional nets. Even if they showed a good efficacy in control conditions, their efficacy in the field, particularly in areas with resistance of Anopheles gambiae to pyrethroids, is not well documented. This study compares wide $\left(\right.$ Olyset $\left.^{\circledR}\right)$ and small $\left(\right.$ Permanet $\left.{ }^{\circledR}\right)$ mesh LLINs in field conditions, using entomological parameters.
\end{abstract}

Methods: The two LLINs were tested in a rice-growing area of south-western Burkina Faso (West Africa) with year around high density of the main malaria vector An. gambiae s.s. In the study village (VK6), there is a mixed population of two molecular forms of An. gambiae, the S-form which dominates during the rainy season and the M-form which dominates the rest of the year. The two LLINs Olyset ${ }^{\circledR}$ and Permanet ${ }^{\circledR}$ were distributed in the village and 20 matched houses were selected for comparison with four houses without treated nets.

Results: Mosquito entrance rate was ten fold higher in control houses than in houses with LLINs and there was no difference between the two net types. Among mosquitoes found in the houses, $36 \%$ were dead in LLIN houses compared to $0 \%$ in control houses. Blood feeding rate was $80 \%$ in control houses compared to $43 \%$ in LLIN houses. The type of net did not significantly impact any of these parameters. No mosquitoes were found inside Permanet ${ }^{\circledR}$, whereas dead or dying mosquitoes were collected inside the Olyset ${ }^{\circledR}$. More than $60 \%$ of mosquitoes found on top or inside the nets had had blood meals from cattle, as shown by ELISA analysis.

Conclusion: The percentage of blood-fed mosquitoes in a bed net study does not necessarily determine net success. The efficacy of the two types of LLINs was comparable, during a period when the S-form of An. gambiae was carrying the $k d r$ gene. Significantly higher numbers of mosquitoes were collected in control houses compared to intervention houses, indicating that the LLINs provided an additional deterrent effect, which enhanced their expected prevention capacity. 


\section{Background}

The use of insecticide-treated bed nets (ITNs) for individual as for collective protection against malaria has been shown to reduce morbidity of childhood malaria (below five years of age) by $50 \%$ and global child mortality by $20 \%-30 \%$ [1-3]. ITNs are now considered to represent efficient tools for malaria vector control, when used on a large scale $[4,5]$. One of the key issues for their use on a large scale is the impregnation and the re-impregnation that needs technical skills and materials, which may not always be available [6]. Preliminary surveys have shown that less than $5 \%$ of nets available in Africa were properly treated or re-treated. The use of mosquito nets pre-treated with insecticide, Long Lasting Impregnated Nets (LLINs), that last the life span of the net, is a solution to this problem [7]. Two LLINs are now available and have been preliminarly recommended by WHO for malaria prevention: the Olyset ${ }^{\circledast}$ [8] net, made of polyethylene netting material (mesh 20 holes $/ \mathrm{cm}^{2}$ ) with permethrin (2\% of concentration) incorporated into the polymer before monofilament yarn extrusion, and the Permanet ${ }^{\circledR}[9]$ net, made of polyester netting material (mesh 25 holes $/ \mathrm{cm}^{2}$ ) with deltamethrin incorporated ( $55 \mathrm{mg} \mathrm{ai} / \mathrm{m}^{2}$ ) in a resin coating of the fibers.

Resistance to the insecticides used for impregnation may be a limiting factor to impregnated nets in vector control. Pyrethroid resistance of the most important African malaria vector Anopheles gambiae s.s. is already widespread in several West African countries [10,11]. A common resistance is caused by the $k d r$ mutation that occasionally is found at very high frequency (>90\%) [12,13]. Fortunately, the predominant $\mathrm{kdr}$ mechanism apparently does not prevent the efficacy of pyrethroid-treated bed nets $[14,15]$. Contrary to West Africa, malaria vector control failure due to metabolic-based resistance on pyrethroid efficacy was reported in South Africa. This resistance is closely associated with the presence of a high level of oxidase activity and sometimes conferring cross-resistance to the carbamate insecticide in the local vector Anopheles

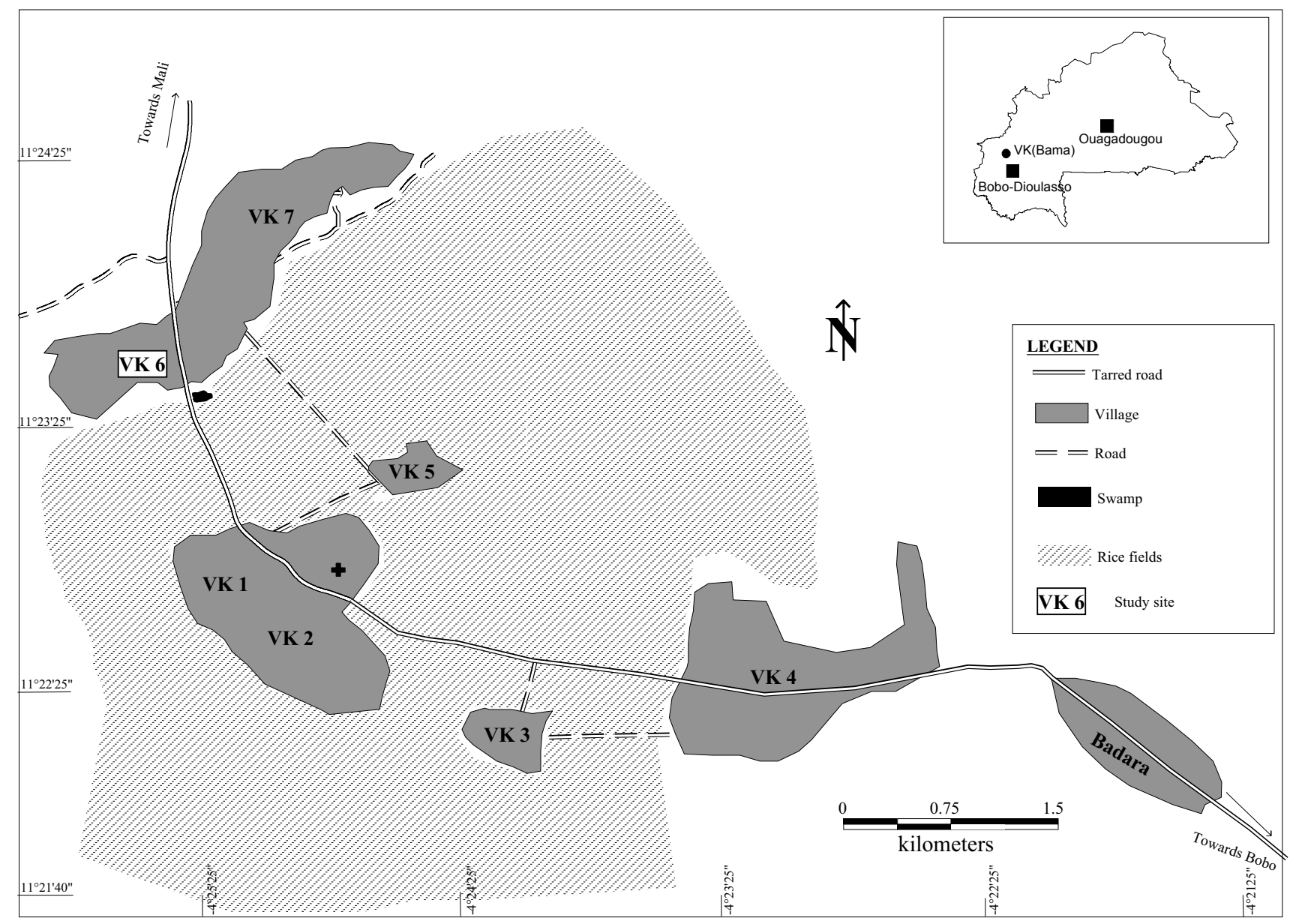

Figure I

Location of the study site. 
funestus, as recently mentioned in Kwazulu Natal and Mozambique (16-17). This oxydase-based resistance has been also observed in An. gambiae populations from Cameroon $[18,19]$ and Kenya [20]. Bed nets without insecticide can never provide complete protection against bloodquesting mosquitoes. However, when treated with pyrethroids, they reduce the number of mosquitoes entering houses and further reduce the blood-feeding rates of those entering. Torn impregnated nets have been shown still to reduce host/vector contact, and it has been argued that the most important effect of ITN is the mass effect on mosquitoes, whether it is before or after biting $[3,21]$. However, some authors considered that to be most effective, impregnated nets should have no holes, no entry flaps and should be tucked in under a mattress, which will not allow mosquitoes access inside the bed net [22]. It is likely that most people primarily acquire and use bed nets for their individual protection against mosquitoes biting $[23,24]$.

It has been shown that mosquitoes with kdr resistance are less susceptible to the excito-repellent effect of pyrethroids [25] and it may, therefore, be possible that such mosquitoes will enter the wider meshed Olyset ${ }^{\circledast}$ net and bite even when this net is still intact. Therefore, in contrast to most published studies, this study compares intact LLINs with wide $\left(\right.$ Olyset $\left.^{\circledR}\right)$ and small (Permanet ${ }^{\circledR}$ ) mesh on the entomological parameters in an area with kdr-An. gambiae populations.

\section{Materials and methods Study area}

The survey was conducted in "Vallée du Kou", a rice growing area of southern Burkina Faso, West Africa. It is located at $30 \mathrm{~km}$ in the North of Bobo-Dioulasso between $4^{\circ} 24^{\prime} 42^{\prime \prime}$ longitude west and $11^{\circ} 23^{\prime} 14^{\prime \prime}$ latitude north and is composed of 7 villages with a total of 4,470 habitants (Figure 1). Irrigation exists in this area since 1972, and is now sub-permanent with two crops grown per year: from February to June during the dry season and from July to November during the rainy season. An unprotected human sleeping in the central rice-field area (VK5) is exposed to more than 60,000 mosquito bites/year [30]. An. gambiae and An. funestus are the two major vectors present. Anopheles arabiensis is rare and found in sympatry with An. gambiae in the surrounding savannah. The two molecular forms $\mathrm{M}$ and $\mathrm{S}$ of An. gambiae were observed in the periphery of the rice field during the rainy season. Huge amount of insecticides, mainly pyrethroids, are used to protect cotton from pest attacks in the neighbouring savannah. Previous studies conducted in this area found resistant An. gambiae populations to permethrin and deltamethrin in the periphery of the rice fields, but susceptible in the centre. This resistance is due to the $\mathrm{kdr}$ mutation, which occurs in the An. gambiae S-form popu- lation (95\%), particularly at the end of the rainy season [11]. The kdr mutation was also observed in the $\mathrm{M}$ form in a very low proportion (4\%) [13]. For these reasons and especially because of the high vector density throughout the year, the village of VK6 was selected to study the personal protection by Permanet ${ }^{\circledast}$ and Olyset ${ }^{\circledR}$ nets.

\section{Entomological survey}

Mosquitoes collection

In total, 20 households matched in size and near the periphery of the rice field were equipped with Permanet ${ }^{\varpi}$ and Olyset ${ }^{\circledast}$ nets. Matched houses with either a Permanet ${ }^{\circledast}$ or an Olyset ${ }^{\oplus}$ net were not more than 50 metres apart. Mosquitoes were collected four days/month from September to November 2003. Volunteer, informed-sleepers caught blood-seeking mosquitoes in the nets from 8:00 $\mathrm{pm}$ to $12: 00 \mathrm{pm}$ and again in the early morning at $6: 00$ $\mathrm{am}$. Residual resting indoor fauna was collected in the houses early in the morning by manual aspirators. All nets were inspected to ensure that they had no holes, no entry flaps and were tucked in under the beds. All mosquitoes found in the nets, on the nets or indoor resting or dead on the floor were collected, counted and morphologically identified. Mosquitoes were classified according to physiological status (unfed, fed and gravid). Mosquitoes collection in the morning at 6:00 am was performed in four houses without any insecticide-treated objects or nets as control. In these control houses, from 6:00 pm to 12:00 pm, blood- seeking females were caught as above and volunteers slept after 12:00 pm under their own untreated nets usually used for personal protection.

\section{Bloodmeal identification}

The origin of bloodmeals from fed females captured above and inside the nets were identified as human or bovine using an enzyme-linked immunosorbent assay (ELISA), as described by Beier et al. [26]. In total, 45 fedmosquitoes, respectively 24 and 21 from Olyset ${ }^{\circledR}$ and Permanet ${ }^{\oplus}$, representing exclusively malaria vectors were analysed by ELISA.

\section{Species and molecular forms of An. gambiae identification and kdr mutation distribution}

A sample of 44 An. gambiae collected above and inside the nets (half from both Olyset ${ }^{\varpi}$ and Permanet ${ }^{\varpi}$ ) was selected for PCR test. Genomic DNA was extracted from single mosquitoes and PCR amplified to identify the species within An. gambiae complex [27], to determine the molecular form (M or S) within the species An. gambiae [28], and, finally, to detect the kdr mutation [29].

\section{Statistical analyses}

Four parameters were compared between the two LLINs: (i) the percentage of house entering (compared to entrance in control houses), (ii) the number of mosqui- 
Table I: Global house entering rate by mosquitoes (percentages are noted in italic) [In each line or row, values sharing a superscript letter are significantly different at $95 \%$ confidence interval]

\begin{tabular}{lcccc}
\hline Mosquito species & Control & LLINs houses & Type of LLINs \\
\cline { 3 - 5 } & & & Olyset $^{\circledR}$ & Permanet $^{\circledR}$ \\
\hline An. gambiae & 8,350 & 1,263 & 633 & 630 \\
& $92^{*}$ & $81.9^{*}$ & 85.8 & 3.3 \\
An. funestus & 110 & 95 & 32 & 7.8 \\
C. quinquefasciatus & 1.2 & $6.2^{*}$ & 185 & 112 \\
Entry rate & 618 & $12^{*}$ & 9.3 & 13.9 \\
\hline \% Deterrency & $6.8^{*}$ & $14.5^{*}$ & 6.9 & 7.6 \\
\hline
\end{tabular}

* Significantly different $P<0.05$

toes collected above and inside the nets, (iii) the fed rate and (iv) the mortality rate. For each entomological parameter, comparison between treatment was made by performing a two way analysis of variance (ANOVA) and a chi square test at $95 \%$ confidence interval.

\section{Results}

Mosquito house entering rate and mosquito house location

\section{Global house entering rate}

In total 10,621 mosquitoes were collected during the study (Table 1) and consisted mainly of Anopheles and Culex with unfed, fed, gravid, half gravid, alive or dead mosquitoes from both control and LLINs-equipped houses. 9,078 mosquitoes were caught in control houses by morning capture, while only 1,543 mosquitoes were collected in either Olyset ${ }^{\circledR}$ or Permanet ${ }^{\circledast}$ LLINs-equipped houses during night and in morning capture. The total number of mosquitoes collected from the different LLINs did not differ significantly $(P>0.05)$. The deterrency rate of the two LLINs was similar, averaging respectively $92 \%$ and $91 \%$ in Olyset ${ }^{\circledast}$ and Permanet ${ }^{\circledast}$ equipped houses. The global deterrent effect, calculated as the difference of entering rates between control and total of LLINs-equipped houses, was estimated to 83\% (Table 1). Globally, Anopheles were significantly more numerous than Culex quinquefasciatus irrespective of the LLINs $(P=0.01)$. Whatever the LLINs, An. gambiae was the most frequent mosquito, reaching $82 \%$, followed by C. quinquefasciatus with $12 \%$ and An. funestus with $6.2 \%$.

\section{Mosquito house location}

Mosquitoes were collected dead or alive, above or inside the nets (both Permanet ${ }^{\circledast}$ and Olyset ${ }^{\circledast}$ ) and indoor elsewhere in the house (Table 2). The number of indoor resting mosquitoes did not differ significantly with the two types of LLINs (491 for Permanet ${ }^{\varpi}, 506$ for Olyset $^{\circledR}$ ) and this was significantly higher than the number of mosquitoes collected from the nets (above and inside) whatever the LLINs $(\mathrm{P}<0.05)$. The proportion of mosquitoes found above the nets and inside the nets was similar for the two types of nets $(P>0.05)$ with respectively $33.5 \%$ and $37.1 \%$ for Olyset ${ }^{\circledast}$ and Permanet $^{\circledast}$ equipped houses. The number of mosquitoes collected above the nets was two fold higher on Permanet ${ }^{\circledast}$ than on Olyset ${ }^{\circledast}$. While dead mosquitoes from Permanet ${ }^{\circledast}$ were exclusively collected above the net, half of them from Olyset $^{\oplus}$ were collected inside the net.

Table 2: Comparison of the proportion of mosquitoes according to their collection place in the LLINs equipped-houses (percentages are noted in italic) [In each line, values sharing a superscript letter are significantly different at $95 \%$ confidence interval

\begin{tabular}{|c|c|c|c|c|c|c|c|c|c|c|}
\hline \multirow[t]{2}{*}{ LLINs } & \multicolumn{3}{|c|}{ Resting indoor } & \multicolumn{3}{|c|}{ Above LLIN } & \multicolumn{3}{|c|}{ Inside LLIN } & \multirow[t]{2}{*}{ Total } \\
\hline & $A g^{\prime}$ & Af & $\mathrm{Cq}$ & $\mathrm{Ag}$ & Af & $\mathrm{Cq}$ & $\mathrm{Ag}$ & Af & $\mathrm{Cq}$ & \\
\hline \multirow[t]{2}{*}{ Olyset $^{\circledR}$} & 398 & 27 & 66 & 128 & 2 & 2 & 107 & 3 & 5 & 738 \\
\hline & $53.9 *$ & 3.7 & 8.9 & $17.3^{*}$ & 0.3 & 0.3 & $14.5^{*}$ & 0.4 & 0.7 & \\
\hline \multirow[t]{2}{*}{ Permanet $^{\circledR}$} & 363 & 41 & 102 & 267 & 22 & 10 & 0 & 0 & 0 & 805 \\
\hline & $45 . I^{*}$ & 5.1 & 12.7 & $33.2^{*}$ & 2.7 & 1.2 & - & - & - & \\
\hline
\end{tabular}

\footnotetext{
*significantly different $P<0.05$ 'Ag : Anopheles gambiae, Af : An. funestus., $\mathrm{Cq}$ : Culex quinquefasciatus
} 
Table 3: Comparison of the global mortality rate and the mortality rates following the mosquito collection place in the two LLINs equipped houses (percentages are noted in italic)

\begin{tabular}{|c|c|c|c|c|c|c|c|c|c|c|}
\hline \multirow[t]{2}{*}{ Mosquito status } & \multirow[t]{2}{*}{ Mosquito collection place } & \multicolumn{3}{|c|}{ Olyset ${ }^{\circledR}$ house } & \multicolumn{3}{|c|}{ Permanet $^{\circledR}$ house } & \multicolumn{3}{|c|}{ Control house } \\
\hline & & $\mathrm{Ag}$ & Af & $\mathrm{Cq}$ & $\mathrm{Ag}$ & Af & $\mathrm{Cq}$ & $\mathrm{Ag}$ & Af & $\mathrm{Cq}$ \\
\hline & Above LLIN & 128 & 2 & 2 & 267 & 22 & 10 & - & - & - \\
\hline \multirow[t]{4}{*}{ Dead } & Inside LLIN & 107 & 3 & 5 & - & - & - & - & - & - \\
\hline & Resting indoor & 10 & 0 & 3 & 3 & 0 & 0 & - & - & - \\
\hline & & \multicolumn{3}{|c|}{260} & \multicolumn{3}{|c|}{302} & \multicolumn{3}{|c|}{0} \\
\hline & & \multicolumn{3}{|c|}{35.3} & \multicolumn{3}{|c|}{37.5} & & & \\
\hline \multirow[t]{4}{*}{ Alive } & Above LLIN & 0 & 0 & 0 & 0 & 0 & 0 & 0 & 0 & 0 \\
\hline & Inside LLIN & 0 & 0 & 0 & 0 & 0 & 0 & 0 & 0 & 0 \\
\hline & Resting indoor & 398 & 27 & 66 & 363 & 41 & 102 & 8,350 & 110 & 618 \\
\hline & & 478 & & & 503 & & & 9,808 & & \\
\hline
\end{tabular}

*significantly different, $P<0.05 \mathrm{Ag}=$ Anopheles gambiae; $\mathrm{Af}=$ Anopheles funestus; $\mathrm{Cq}=$ Culex quinquefasciatus

\section{Mortality rate}

The global mortality rate was similar in the two LLINs houses averaging 36\% (Table 4). Compared to the control houses, a high percentage of mortality was recorded in houses equipped with LLINs (36.4\% vs 0\%). The proportion of dead mosquitoes collected above the net was significantly higher $(37.1 \%, \mathrm{n}=299)$ on Permanet $^{\circledR}$ than that on Olyset ${ }^{\circledast}$ net $(17.9 \%, n=132) .15 .6 \%$ of dead mosquitoes were recorded inside Olyset ${ }^{\circledR}$ net while no mosquito was found inside Permanet ${ }^{\circledast}$. No live mosquitoes were caught above or inside the nets, but a total of 17 dying mosquitoes were collected above the two LLINs. The number of dying mosquitoes was similar in the two types of nets and was trivial compared to the total of dead mosquitoes. All mosquitoes in touch with LLINs (above or inside) were dead. Few dead mosquitoes were collected indoor the LLINs houses ( $\mathrm{n}=13$ vs 3 respectively for Olyset $^{\circledR}$ and Permanet ${ }^{\circledR}$ equipped houses). Molecular form identification performed on 44 An. gambiae collected above and inside the nets showed that $88.5 \%$ of An. gambiae tested were of molecular $\mathrm{M}$ form and this proportion did not differ significantly between the two LLINs. The $k d r$ gene was detected only in the all S form tested in PCR ( $\mathrm{n}$ $=5$ ). No An. arabiensis was found in the PCR-analysed mosquitoes.

\section{Mosquito blood-fed status}

Less than $40 \%$ of mosquitoes collected in the LLINs equipped-houses were engorged while $79.8 \%$ were recorded in control houses (Table 5), showing a reduction of the rate of fed females averaging $42 \%$. However, the rate of fed mosquitoes was slightly superior in Olyset ${ }^{\circledR}$ equipped houses, but it did not differ significantly between the two nets $(P>0.05)$. Within the females collected above or inside the nets $(\mathrm{n}=247$ vs 299, respec- tively for Olyset ${ }^{\circledast}$ and Permanet $^{\circledR}$ ), about $7 \%$ were fed mosquitoes regardless of the type of net (Table 5).

\section{Blood meals origin}

Overall, 45 specimens of engorged An. gambiae collected in and above the nets were analysed to determine the source of the bloodmeal. Most of the engorged females were fed on cattle, respectively $62 \%$ and $79 \%$ for Permanet ${ }^{\circledR}$ and Olyset ${ }^{\circledast}$ (Table 6). The rate of mosquitoes fed on humans did not differ significantly $(P>0,05)$ irrespective of the LLIN, reaching respectively $21 \%$ and $30 \%$ for Olyset $^{\circledR}$ and Permanet ${ }^{\circledR}$. The rate of mosquitoes fed on cattle was high in the LLINs equipped-houses.

\section{Discussion}

The study was carried out in a rice field area, where high densities of mosquitoes are observed throughout the year [30]. An. gambiae and C. quinquefasciatus were resistant to pyrethroids in this area and resistance of the An. gambiae $S$ form is pronounced at the end of the rainy season [11]. $K d r$ resistance was also observed in a small proportion (less than 5\%) of An. gambiae $\mathrm{M}$ form, conferring a susceptible status to $\mathrm{M}$ population. But as An. gambiae S form proportion (even during its maximum peak at the end of rainy season) has never gone beyond $30 \%$, the global pyrethroid resistance status of this area is an intermediate resistance one [13]. This intermediate resistance status could probably explain that the two LLINs showed a global efficacy and no differential efficacy level was observed.

These results were consistent with those obtained in experimental huts from the Bouaké region in Côte d'Ivoire concerning the efficacy of LLINs in Anopheles and Culex resistant areas [15]. In contrast, in a resistance area from Danané in the north of Côte d'Ivoire, where the An. 
Table 4: Comparison of the rate of fed and unfed dead females following their collection place in LLINs equipped houses (percentages are noted in italic)

\begin{tabular}{|c|c|c|c|c|c|c|c|c|c|c|}
\hline \multirow[t]{2}{*}{ Mosquito status } & \multirow[t]{2}{*}{ Mosquito collection place } & \multicolumn{3}{|c|}{ Olyset ${ }^{\circledR}$ house } & \multicolumn{3}{|c|}{ Permanet ${ }^{\circledR}$ house } & \multicolumn{3}{|c|}{ Control house } \\
\hline & & $\mathrm{Ag}$ & Af & $\mathrm{Cq}$ & $\mathrm{Ag}$ & Af & $\mathrm{Cq}$ & $\mathrm{Ag}$ & Af & $\mathrm{Cq}$ \\
\hline \multirow[t]{4}{*}{ Unfed } & Above LLIN & 100 & 1 & 1 & 221 & 17 & 9 & - & - & - \\
\hline & Inside LLIN & 84 & 3 & 3 & - & - & - & - & - & - \\
\hline & Resting Indoor & 85 & 8 & 24 & 74 & 12 & 38 & ND & ND & ND \\
\hline & & \multicolumn{3}{|c|}{309} & \multicolumn{3}{|c|}{371} & \multicolumn{3}{|c|}{726} \\
\hline \multirow[t]{5}{*}{ Fed } & Above LLIN & 21 & 1 & 0 & 38 & 4 & 1 & - & - & - \\
\hline & Inside LLIN & 19 & 0 & 2 & - & & - & - & - & - \\
\hline & Resting indoor & 232 & 16 & 21 & 171 & 26 & 25 & 6294 & ND & ND \\
\hline & & \multicolumn{3}{|c|}{312} & \multicolumn{3}{|c|}{265} & \multicolumn{3}{|c|}{7242} \\
\hline & & \multicolumn{3}{|c|}{42.3} & \multicolumn{3}{|c|}{32.9} & \multicolumn{3}{|c|}{$79.8 *$} \\
\hline \multirow[t]{4}{*}{ Gravid } & Above LLIN & 7 & 0 & 1 & 8 & I & 0 & - & - & - \\
\hline & Inside LLIN & 4 & 0 & 21 & - & - & - & - & - & - \\
\hline & Resting indoor & 81 & 3 & 21 & 118 & 3 & 39 & ND & ND & ND \\
\hline & & \multicolumn{3}{|c|}{117} & \multicolumn{3}{|c|}{168} & \multicolumn{3}{|c|}{1110} \\
\hline
\end{tabular}

* significantly different $P<0.05 \mathrm{Ag}=$ Anopheles gambiae; $\mathrm{Af}=$ Anopheles funestus; $\mathrm{Cq}=$ Culex quinquefasciatus $\mathrm{ND}:$ undetermined

gambiae $\mathrm{S}$ form was observed with $80 \%$ of $k d r$, although the permethrin pre-impregnated Olyset nets showed a good mass effect [21], their efficacy on the reduction of entomological inoculation rate decreased significantly [31]. A similar study may be performed with deltamethrin-LLINs (Permanet ${ }^{\circledR}$ ) in a high resistance area, as they would be expected to maintain a better efficacy, as already demonstrated in the semi-natural conditions of experimental huts [14]. Nevertheless, in the intermediate pyrethroids resistance area of the present study, an important mortality was observed both with Permanet ${ }^{\circledR}$ and with Olyset $^{\circledR}$ nets, compare to the control. It is likely that all mosquitoes which have been in contact with the nets were killed. The few dying mosquitoes that were collected above Permanet ${ }^{\circledast}$ and inside Olyset ${ }^{\circledR}$ nets should be considered as truly dead mosquitoes as they were unable to fly away. Furthermore, fed mosquitoes were found dead or dying above Permanet ${ }^{\circledR}$ or above/inside Olyset ${ }^{\circledR}$ nets. That evokes the possibility that these mosquitoes could bite sleepers and transmit malaria in case they were infected before dying especially inside the Olyset ${ }^{\circledR}$ nets. To respond to this question, sleepers were asked to keep awake in the nets and to collect mosquitoes seeking blood meal from 8:00 pm to 12:00 pm. This showed that mosquitoes caught before midnight above or inside the nets were dead or dying and some of them felt through the aperture of the net. Fed as well as unfed mosquitoes were collected in this way. Two hypothesis could be addressed to explain the presence of fed females in LLINs: i) these mosquitoes have engorged first on cattle and, as it is known that An. gambiae bites several times in a gonotrophic cycle [32], they may seek a human host to complete their bloodmeal, even if sleepers are protected by LLINs; ii) the engorged females collected above or inside

Table 5: Bloodmeal origin of fed Anopheles gambiae females from LLINs equipped houses analysed by ELISA (percentages are noted in italic)

\begin{tabular}{|c|c|c|c|c|c|c|}
\hline \multirow{2}{*}{$\begin{array}{l}\text { Source of } \\
\text { Bloodmeal }\end{array}$} & \multicolumn{3}{|c|}{ Olyset $^{\circledR}$} & \multicolumn{3}{|c|}{ Permanet $^{\circledR}$} \\
\hline & Inside & Above & Total & Inside & Above & Total \\
\hline \multirow[t]{2}{*}{ Human } & 3 & 2 & 5 & 0 & 8 & 8 \\
\hline & - & - & $20.8^{*}$ & - & - & $38.1^{*}$ \\
\hline \multirow[t]{2}{*}{ Bovine } & 12 & 7 & 19 & 0 & 13 & 13 \\
\hline & - & - & 79.2 & - & - & 61.9 \\
\hline
\end{tabular}

\footnotetext{
*significantly different, $P<0.05$
} 
the different nets were already blood-fed on cattle and, because in this high anopheline density area An. gambiae is very endophilic as a result of the use of bed nets on a large scale, they come inside houses to rest after feeding, even in LLINs-equipped houses. While seeking a place to rest in these houses, they come in contact with the nets and die.

The bloodmeal identification indicated that the majority of fed females had engorged on cattle, confirming the high zoophilic rate (about $70 \%$ ) of An. gambiae in this particular rice-field area, where Robert et al. [33] also observed high zoophilic rate compared to that of the neighboring savannah villages. This particular zoophilic rate can be explained by i) the proximity of livestock as each household has usually a pair of cattle for rice field tillage living the same concession; ii) because of the high density of mosquitoes in this area with more than 60,000 mosquito bites/year [30], almost every household used nets (but not necessarily treated-nets) for personal protection. For these reasons, An. gambiae (and other species also) developed a zoophilic behaviour for host preference. Nevertheless, some human-bloodfed females were found above and inside LLINs. This relatively low proportion of human-bloodfed mosquitoes (30\%) should have been engorged on the sleepers as shown in a study carried out in Tanzania [34].

A significantly $(P<0.02)$ high proportion of unfed mosquitoes was collected in houses equipped with treated nets compared to control houses. This result confirms that LLINs clearly reduced blood meal rate as had been demonstrated in previous studies on ITNs efficacy carried out in East Africa [24,34,35].

\section{Conclusion}

To conclude, both Permanet ${ }^{\varpi}$ and Olyset ${ }^{\varpi}$ showed a good efficacy against An. gambiae as no live individual was caught above and inside the nets. Moreover, significantly less mosquitoes were collected in treated houses compared to control ones, indicating that these two LLINs provided, in addition to the mosquito mortality, a deterrent effect [36] which enhances their expected prevention capacity. However, this study needs to be performed in a high resistance area, such as the Lena village where An. gambiae populations are dominated by the S form (more than $95 \%$ ) with $90 \%$ of $k d r$ gene [11]: this will permit a more precise evaluation of Permanet ${ }^{\circledast}$ efficacy in an area with pyrethroid resistance.

\section{Authors' contributions}

DKR participated to the study design, undertook the field study, analysed data and wrote the paper. DA participated in the study design, the data analysis and the manuscript drafting. BT participated to the data analysis and interpre- tation, the drafting and the revision of the paper. TPL participated to study design. GTR and OJB are administrative authorities who facilitated the implementation of the study. SO designed the study, participated to the analysis of data and the drafting of the manuscript.

\section{Acknowledgements}

This study was supported by a grant from Vestergaard ${ }^{\circledR}$ company. Authors are grateful to volunteers and households of "Vallée du Kou" who allowed this study to take place.

\section{References}

I. Lengeler C, Cattani J, De Savigny D: Net gain. A new method for preventing malaria deaths. IDRC Otawa/WHO, Geneva; 1996:189.

2. Binka FN, Kubaje A, Adjuik M, Williams LA, Lengeler C, Maude GH, Arma GE, Kajihra B, Adiama JH, Lengeler C, Smith PG: Impact of permethrin treated bed nets in child mortality in KassenaNankana district, Ghana: a randomized controlled trial. Trop Med Int Health 1996, I: I47-I54.

3. Nevill CG, Some ES, Mung'ala VO, Mutemi W, New L, Marsh K, Lengeler C, Snow RW: Insecticide-treated bed nets reduce mortality and severe morbidity from among children on the Kenyan Coast. Trop Med Int Health 1996, I: I39-46.

4. Curtis CF: Appropriate methods of vectors control. Bocca Raton, Florida CRC Press; 1990:5-46.

5. WHO: A global strategy for malaria control, Geneva. 1990:30.

6. Lines J: Mosquito nets and insecticides for nets treatment: a discussion of existing and potential distribution systems in Africa. Trop Med Int Health 1996, 1:616-632.

7. Guillet P, Alnwick D, Cham MK, Neira M, Zaim M, Heymann D, Mukelabai K: Long-lasting treated mosquito nets: a breakthrough in malaria prevention. Bull World Health Organ 200I, 79:998.

8. WHO: Report of the fifth whopes working group meeting (Review of VectoBaWG, Permanet ${ }^{\circledR}$ and Gokilaht-S5EC), Geneva. 2001:43.

9. WHO: Report of the seventh WHOPES working group meeting (Review of VectoBaWG, Permanet ${ }^{\circledR}$ and GokilahtS5EC), Geneva. 2004:78.

10. Chandre F, Darriet F, Manguin S, Brengues C, Carnevale P, Guillet P: Pyrethroid cross resistance spectrum among populations of Anopheles gambiae s.s. from Côte d'Ivoire. J Am Mosq Contr Assoc 1999, I 5:53-59.

II. Diabaté A, Baldet T, Chandre F, Akogbeto M, Guiguemdé TR, Darriet F, Brengues C, Guillet P, Hemingway J, Small G, Hougard JM: The role of agricultural insecticides in Anopheles gambiae s.I. resistance to pyrethroids in Burkina Faso, West Africa. Am J Trop Med Hyg 2002, 67:617-622.

12. Chandre F, Manguin S, Brengues C, Dossou Yovo J, Darriet F, Diabaté A, Carnevale P, Guillet P: Current distribution of pyrethrinoid resistance gene (Kdr) in Anopheles gambiae complex from West Africa and further evidence for reproductive isolation of Mopti form. Parassitology 1999, 41:319-322.

13. Diabaté A, Baldet T, Chandre F, Dabiré KR, Kengne P, Guiguemdé TR, Simard F, Guillet P, Hemingway J, Hougard JM: Kdr Mutation, a Genetic marker to Assess events to Introgression Between the Molecular $M$ and $S$ forms of Anopheles gambiae (Dipterae: Culicidae) in the Tropical Savannah area of West Africa. Entomol Soc America 2003, 40:195-198.

14. Darriet F, Guillet P, N'guessan R, Doannio JMC, Koffi A, Konan LY, Carnevale $P$ : Impact de la résistance aux pyréthrinoïdes sur l'efficacité des moustiquaires imprégnées dans la prévention du paludisme: résultats des essais en cases expérimentales avec la deltaméthrine. Bull Soc Path Exot 2000, 93(Suppl 2): $131-134$.

15. Darriet F, Guillet P, N'guessan R, Doannio JMC, Koffi A, Konan LY, Carnevale $P$ : Impact de la résistance d'Anopheles gambiae ss à la perméthrine et à la deltaméthrine sur l'efficacité des moustiquaires imprégnées. Med Trop 2000, 58:349-354. 
16. Hargreaves K, Koekemoer LL, Brooke BD, Hunt RH, Mthembe J, Coetzee M: Anopheles funestus resistant to pyrethroids insecticides in South Africa. Med Vet Entomol 2000, 2:181-189.

I7. Brooke BD, Kloke G, Hunt RH, Koekemoer LL, Temu EA, Taylor ME, Small G, Hemingway J, Coetzee M: Bioassay and biochemical analyses of insecticide resistance in southern African Anopheles funestus (Diptera : Culicidae). Bull Entomol Res 200I, 91:265-272.

18. Etang J, Manga L, Chandre F, Guillet P, Fondjo E, Mimpfoundi R, Toto JC, Fontenille D: Insecticide Susceptibility status of Anopheles gambiae s.I. (Diptera : Culicidae) in Republic of Cameroon. J Med Entomol 2003, 4:492-497.

19. Etang J, Chandre F, Guillet P, Manga L: Reduced bio-efficacy of permethrin EC imprenated bed nets against an Anopheles gambiae strain with oxidase-based pyrethroid tolerance. Malar J 2005, 3:46.

20. Vulule JM, Beach RF, Atieli FK, McAllister JC, Brogdon WG, Roberts JM, Mwangui RW, Hawley WA: Elevated oxidase and esterase levels associated with permethrin tolerance in Anopheles gambiae from Kenya villages using permethrin-impregnated nets. Med Vet 1999, I 3:239-244.

21. Henry MC, Doanio JMC, Darriet F, Nzeyimana I, Carnevale P: Efficacité des moustiquaires pré-imprégnées de permethrine OLYSET ${ }^{\circledR}$ Nets en zone de resistance des vecteurs aux pyrethrinoides II. Evaluation parasito-clinique. Med Trop 1999, 59:355-357.

22. Lindsay SW, Snow RW, Bloomfield GL, Janneh MS, Wirtz RA, Greenwood BM: Impact of permethrin-treated bed nets on malaria transmission by the Anopheles gambiae complex in the Gambia. Med Vet Entomol 1989, 3:263-27I.

23. Van Bortel W, Barutwanonyo $M$, Delacolette $C$, Coosemans $M$ : Motivation to acquire and use impregnated mosquito in a stable malaria zone in Burundi. Trop Med Int Health 1996, I:7|-80.

24. Binka FN, Adongo P: Acceptability and use for insecticide ednets in northern Ghana. Trop Med Int Health 1997, 2:499-507.

25. Corbel V, Chandre F, Brengues C, Akogbeto M, Lardeux F, Hougard $J M$, Guillet P: Dosage-dependent effects of permethrin-treated nets on the behaviour of Anopheles gambiae and the selection of pyrethroid resistance. Malar J 2004, 3:22.

26. Beier JC, Perkins PV, Wirtz RA, Koros J, Diggs D, Gargan TPII, Koech DK: Bloodmeal identification by direct enzyme linked immunosorbent assay (ELISA), tested on Anopheles (Diptera : Culicidae) in Kenya. J Med Ent I986, 25:9-16.

27. Scott JA, Brogdon WD, Collins FH: Identification of single specimens of Anopheles gambiae complex by the polymerase chain reaction. Am J Trop Med Hyg 1993, 49:520-529.

28. Favia G, Lanfroncotti A, Spanos L, Sidén-Kiamos I, Louis C: Molecular characterisation of ribosomal polymorphisms discriminating among chromosomal forms of Anopheles gambiae ss. Insect Mol Biol 200I, I0:19-30.

29. Martinez-Torres D, Chandre F, Williamson MS, Darriet F, Berge JB, Devonshire AL, Guillet P, Pasteur N, Pauron D: Molecular characterization of pyrethroid knockdown resistance (kdr) in the major malaria vector Anopheles gambiae s.s. Insect $\mathrm{Mol} \mathrm{Biol}$ 1998, 7:179-84.

30. Baldet T, Diabaté A, Guiguemdé TR: Etude de la transmission du paludisme en 1999 dans la zone rizicole de la Vallée du Kou (Bama) Burkina Faso. Cahiers Santé 2003, I3:55-60.

31. Doannio JMC, Dossou-Yovo J, Diarrasouba G, Chauvancy G, Darriet F, Chandre F, Henry MC, Nzeymana I, Guillet P, Carnevale P: Efficacité des moustiquaires pré-impregnées de perméthrine OLYSET ${ }^{\circledR}$ en zone de résistance des vecteurs aux pyrethrinoïdes I. Evaluation entomologique. Med Trop 1999, 59:349-354.

32. Koella JC, Sorensen FL, Anderson RA: The malaria parasite Plasmodium falciparum increases the frequency of multiple feedings of its mosquito vector, Anopheles gambiae. Proc $R$ Soc Lond Biol Sc 1998, 265:763-768.

33. Robert V, Gazin P, Carnevale P: Malaria transmission in three sites surrounding the area of Bobo-Dioulasso (Burkina Faso): the savanna, a rice field and the city. Bull Soc Vect Ecol 1986, 1 2:54|-543.

34. Lines J, Lengeler C, Cham K, de Savigny D, Chimumbwa J, Langi P, Carroll D, Mills A, Hanson K, Webster J, Lynch M, Addington W, Hill J, Rowland M, Worrall E, MacDonald M, Kilian A: Scaling-up and sustaining insecticide-treated net coverage. Lancet Infect Dis 2003, 3:465-466.

35. Soremekun S, Maxwell C, Zuwakuu, Chen C, Michael E: Measuring the efficacy of insecticide treated bed nets: the use of DNA fingerprinting to increase the accuracy of personal protection estimates in Tanzania. Trop Med Int Health 2004, 9:664-672.

36. Maxwell CA, Chambo W, Mwaimu M, Magogo F, Carneiro IA, Curtis CF: Variation of malaria transmission and morbidity with altitude in Tanzania and with introduction of alphacypermethrin treated nets. Malar J 2003, 2:28.
Publish with Bio Med Central and every scientist can read your work free of charge

"BioMed Central will be the most significant development for disseminating the results of biomedical research in our lifetime. "

Sir Paul Nurse, Cancer Research UK

Your research papers will be:

- available free of charge to the entire biomedical community

- peer reviewed and published immediately upon acceptance

- cited in PubMed and archived on PubMed Central

- yours - you keep the copyright

Submit your manuscript here:

http://www.biomedcentral.com/info/publishing_adv.asp
BioMedcentral 